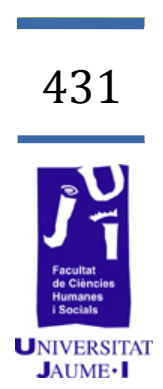

\title{
Avaluació de la competència emocional a través d'una app en un nen amb trastorn de l'espectre autista (nivell 1)
}

Irene Benedito Sánchez ibenedit@uji.es Eloy Soria-Izquierdo esoria@uji.es Clara Andrés-Roqueta candres@psi.uji.es 
Els nens i nenes amb trastorns de l'espectre autista (TEA) demostren dificultats en l'àrea de competència emocional en diversos components més enllà del reconeixement d'expressions facials. Existeixen distintes eines (analògiques i digitals) per a avaluar les habilitats emocionals dels nens amb TEA, però la major part avaluen aspectes parcials d'aquesta competència.

Per tant, en el present estudi es pretén administrar de manera pilot l'aplicació mòbil (app) EMOCIONATEST per a avaluar la competència emocional per a nens i nenes de 3 a 12 anys en un nen amb TEA nivell 1 de 12 anys, i comparar-la amb la d'un nen sense TEA de la mateixa edat, per detectar possibles diferències en l'execució i decidir les millores escaients per a la ferramenta. L'app té 5 nivells de dificultat basats en les fites evolutives del desenvolupament emocional típic en l'edat infantil: reconeixement d'expressions facials; construcció d'expressions facials; identificació d'emocions a partir de situacions comuns; reconeixement d'emocions basades en experiències cognitives; reconeixement d'emocions ocultes. Aquesta app es trobava en fase experimental i ha estat dissenyada per investigadors de la Universitat Jaume I de Castelló (UJI).

Després d'avaluar els dos nens amb l'app, s'han trobat diferències pel que fa a la resolució correcta de cada nivell, i s'ha vist que té més dificultat per a resoldre els ítems en general el nen diagnosticat amb TEA. Es conclou que la ferramenta presentada permet avaluar la competència emocional en nens i nenes d'edat escolar i també establir diferències entre nens i nenes amb dificultats. Així mateix, s'aprecien distintes millores que cal realitzar en l'aplicació en fase experimental, de cara a obtenir la versió final. Les millores en l'app i la validació d'aquesta en població amb i sense problemes permetran oferir a la comunitat psicoeducativa una ferramenta útil i motivadora que serà interessant per als professionals que treballen amb aquesta població.

Paraules clau: trastorn de l'espectre autista (TEA), competència emocional, aplicació mòbil (app) i avaluació.

\section{Introducció}

Segons l'actual manual diagnòstic i estadístic dels trastorns mentals (DSM-5, American Psychiatric Association - APA, 2013), els nens i nenes amb trastorn de l'espectre autista (TEA) es caracteritzen per la presència de dèficits persistents en la comunicació social i la interacció social donats en diversos contextos (dèficits en reciprocitat socioemocional, dèficits en conductes comunicatives no verbals emprades en la interacció social o dèficits per a desenvolupar, mantenir o comprendre relacions) i patrons 
repetitius i restringits de conductes, activitats o interessos, caracteritzats per moviments motors, ús d'objectes o parla estereotipada o repetitiva; insistència en la igualtat; interessos altament restringits i hipereactivitat 0 hiporeactivitat sensorial (APA, 2013).

A més, com a canvi notable en aquesta nova edició del manual diagnòstic, el DSM-5 classifica diversos nivells de TEA dins d'aquest trastorn segons la severitat d'aquest, i són els següents:

- Nivell 1: necessita suport. Mostren dificultats iniciant interaccions socials $\mathrm{i}$ inflexibilitat en el comportament de manera que causa interferència significativa en el funcionament en un context o més.

- Nivell 2: requereixen un suport substancial. Mostren dificultats marcades en habilitats de la comunicació social (verbal i no verbal). El comportament inflexible i les dificultats per a afrontar el canvi apareixen amb freqüència en varietat de contextos.

- Nivell 3: requereixen un suport molt substancial. Mostren dificultats greus en habilitats de comunicació social (verbal i no verbal que causen alteracions greus en el funcionament. La inflexibilitat del comportament i les dificultats extremes per a afrontar els canvis interfereixen en tots els contextos.

Des de fa alguns anys, tant en l'àmbit de la psicologia com en l'educació han aprofundit en l'estudi del món de les emocions, de manera que ha augmentat el nombre de publicacions i teories que reconeixen la rellevància de les emocions en la vida social, l'evolució d'aquestes i repercussions al llarg del desenvolupament i la importància d'arribar a ser «social i emocionalment competent» (Giménez-Dasí i Quintanilla, 2009). En aquest àmbit, s'han observat que els nens diagnosticats amb TEA mostren diverses dificultats, anomenades anteriorment en els diferents nivells de severitat.

Els nens amb TEA es caracteritzen per mostrar un deteriorament greu en la flexibilitat cognitiva i la interacció social i poden ser variables en les seues habilitats de comunicació. Dins de l'àrea de la interacció social, durant el desenvolupament d'aquesta, els nens i nenes amb TEA mostren importants alteracions en la seua competència emocional (Deruelle et al., 2004), que s'observen tant mitjançant les seues conductes no verbals (com ara, en la dificultat per a establir contacte visual, per a comprendre i expressar facialment les emocions o per a regular la postura corporal) com verbals (com ara, la dificultat per a empatitzar amb els altres o per compartir interessos o plaers) (American Psychiatric Association - APA, 2008).

Les investigacions entorn d'aquesta àrea han vinculat aquest dèficit en la competència emocional als problemes en la seua capacitat de teoria de la ment, és a dir, la capacitat de predir el comportament de la gent diferenciant entre la realitat $i$ els seus estats mentals (Baron-Cohen, 
Wheelwright, Hill, Raste i Plumb, 2001). Actualment, es coneix que aquests nens no tenen massa problemes en la gestió i en el reconeixement de les emocions bàsiques (Grossman, Klin, Carter i Volkmar, 2000), però sí que mostren problemes en la incapacitat de comprendre el context en què es produeixen (causes internes o externes), a causa de l'ús parcial de la informació continguda en la situació, així com de la tendència a prestar més atenció als detalls físics o explícits que als detalls socials relacionats amb l'emoció (Klin, 2000). Per tant, és evident que els nenes i nenes amb TEA necessiten ajuda tant en la comprensió i l'expressió d'emocions pròpies (i d'altres), com en el processament de la informació social relacionada amb ells en diverses situacions.

No obstant això, cal assenyalar que existeix certa discrepància respecte d'aquesta postura: mentre alguns autors demostren l'existència d'un dèficit o trastorn sever en aquesta competència emocional (Deruelle et al., 2004; Hobson, 1986; Yirmiya et al., 1992), altres autors han demostrat que no hi ha excessius problemes en el maneig i reconeixement de les emocions bàsiques (Grossman, Klin, Carter i Volkmar 2000; Loveland et al., 1997), o que el problema està relacionat amb la incompetència per a generar una coherència contextual adient, causa de l'ús parcial de la informació que es dóna en la situació (Frith, 2003).

El que sí que està clar és que aquestes dificultats en la comprensió de les emocions pròpies i d'altres persones els impedeixen formar relacions de qualitat amb els seus iguals durant l'edat de l'escolaritat primària als centres ordinaris, situació que s'agreuja en l'etapa de secundària. Actualment, diversos estudis d'intervenció han demostrat la possibilitat de millorar la competència emocional d'aquests nens i nenes. Encara així, la majoria d'aquests estudis s'han centrat en aspectes parcials de la competència emocional i s'han caracteritzat per una falta de rigor científic i metodològic que ha fet impossible demostrar-ne l'efectivitat.

Conseqüentment, aquests nens estan en risc de caure en un bucle de reclusió social i cal crear mètodes educatius per a treballar el món social des de situacions estructurades (com l'aula ordinària o dins d'aules específiques integrades en escoles ordinàries) per posar en pràctica aquestes habilitats i generalitzar a situacions no reglades de la vida quotidiana (exemple: patis o sortides extraescolars). D'aquesta manera, per proveir a aquests nens d'aquestes habilitats, entre les quals destaquen les habilitats interpersonals relacionades amb la comprensió emocional, una bona intervenció hauria d'incloure l'entrenament en diferents episodis socioemocionals quotidians $i$ adequats a la seua edat $i$ sexe. A més, sense una bona intervenció en l'àrea socioemocional, aquesta situació s'agreuja durant l'etapa de secundària.

Durant els últims anys, s'han generat diverses ferramentes des de l'àmbit de les Tecnologies de la Informació i la Comunicació (TIC) per compensar les dificultats dels nens i nenes amb TEA, ja que s'adapten més bé a la seua manera de processar la informació (Gómez i García, 
2012). A més, l'equipament en TIC als centres escolars (pissarres digitals, tabletes, etc.) s'ha incrementat notablement com a indicador de qualitat $\mathrm{i}$ de millora dels processos d'ensenyament-aprenentatge.

A més a més, s'ha donat un creixent interés de les famílies d'aquests nens i nenes per obtenir un suport que puga utilitzar-se també a casa, $i$ així complementar i donar seguiment als avanços que es fan a l'escola. En aquest sentit, recentment s'ha promogut l'ús dels videojocs i aplicacions mòbils, ja que inclouen un component lúdic i motivador en l'aprenentatge, encara que molts han sigut dissenyats amb finalitats comercials i manquen de les didàctiques. Per aquesta raó, es detecta la necessitat de dissenyar amb una base científica, una ferramenta que puga utilitzar-se en distints àmbits: classe ordinària, individualment, classe de xicotet grup, a classe d'audiovisuals o a casa.

Per tot allò comentat en els paràgrafs anteriors, es detecta la necessitat de dissenyar amb una base científica una ferramenta que es puga usar en diferents escenaris: classe ordinària, individualment, classe de petit grup, classe d'ordinadors o casa. Així, es desenvolupa una aplicació mòbil (tant aplicació web com aplicació nativa) per a l'avaluació de la competència emocional en nens amb TEA (EMOCIONATEST; dissenyada a I'UJI per un grup d'investigació), el disseny de la qual està basat en l'anàlisi d'estudis evolutius sobre desenvolupament d'emocions en població amb desenvolupament típic i amb TEA. Aquesta app va dirigida a nens $\mathrm{i}$ nenes amb TEA de 6 a 12 anys i combina un mètode d'intervenció lúdic en competència emocional (amb diferents nivells de dificultat) i un sistema d'avaluació d'aquesta competència.

\section{Objectius}

Una vegada explicada anteriorment la utilitat i la conveniència d'aquesta app com a ferramenta per a avaluar la comprensió emocional en les diverses edats escolars, es detallen els objectius d'aquest estudi.

El primer objectiu és comparar el funcionament de l'app com a instrument d'avaluació en un nen de 12 anys amb TEA nivell 1 (TEA N1) i un altre de la mateixa edat amb desenvolupament típic (DT).

Sota aquest primer objectiu, es planteja la hipòtesis principal de l'estudi segons estudis previs: s'apreciaran diferències en l'execució de l'app entre els dos casos (DT i TEA N1).

El segon objectiu del estudi és provar de manera pilot l'eficàcia de I'app EMOCIONATEST ( $i$ tots els seus nivells) com a ferramenta per a avaluar de manera comprensiva la competència emocional en nens $i$ nenes amb TEA entre 3 i 12 anys. 


\subsection{Mostra}

Per poder complir els objectius d'aquest estudi, és a dir, comparar el funcionament de l'app com a instrument d'avaluació, es va procedir a seleccionar un nen de 12 anys amb TEA N1 i un altre de la mateixa edat amb DT.

El model seguit en aquesta estudi és la comparació de dos casos:

Participant amb TEA: és un nen de gènere masculí, de 12 anys d'edat i amb diagnòstic de TEA nivell 1 , que va ser seleccionat d'un gabinet psicopedagògic privat (on li havien realitzat el diagnòstic de TEA i on rebia setmanalment suport fora de l'horari escolar).

Participant amb Desenvolupament Típic (DT): paral-lelament, es va seleccionar com a subjecte control (d'edat i gènere) un altre nen de la mateixa edat (12 anys) amb DT d'un centre escolar privat de la província de Castelló.

\subsection{Instruments}

L'instrument utilitzat en el present estudi ha sigut l'app EMOCIONATEST. Aquesta aplicació mòbil s'ha dissenyat per a l'avaluació de la competència emocional en nens i nenes amb TEA entre 3 i 12 anys.

El disseny es basa, d'una banda, en l'anàlisi d'estudis evolutius sobre desenvolupament d'emocions anteriorment esmentats, ja que es busca abordar la competència emocional d'una manera comprensiva, i de l'altra, en les particularitats per a processar, comprendre, expressar i reaccionar davant les emocions dels nens amb TEA .

Aquesta aplicació s'estructura en cinc nivells de dificultat creixent, amb 12 ítems cadascun. És a dir, oscillla entre el nivell més fàcil (nivell 1) i el més difícil (nivell 5). Per a cada bloc d'ítems, els protagonistes de les històries són $50 \%$ dels ítems xics i en el $50 \%$, xiques.

La durada aproximada de l'administració individual de la prova és de 20 minuts (depenent de l'edat i dificultats de cada nen/a) i es disposa d'un manual d'aplicació per al professional on estan narrades les ajudes verbals per a cada història.

A continuació, es descriuen aquests cinc nivells.

Nivell 1: Reconeixement de l'expressió facial

L'objectiu d'aquest nivell és que el nen identifique una emoció entre diverses expressions facials presentades. Se'ls mostren sis expressions facials i se'ls demana que seleccionen d'aquestes la que és correcta per a una emoció específica, així ells hauran de seleccionar la cara que mostra l'emoció correcta dins de les diverses opcions.

Hi ha un total de 12 ítems (dos per a cada expressió facial: feliç, trist, fàstic, por, enuig, sorpresa). En la Figura 1 s'adjunta un exemple d'un dels ítems (masculí) per a avaluar la identificació de l'expressió facial felicitat. 

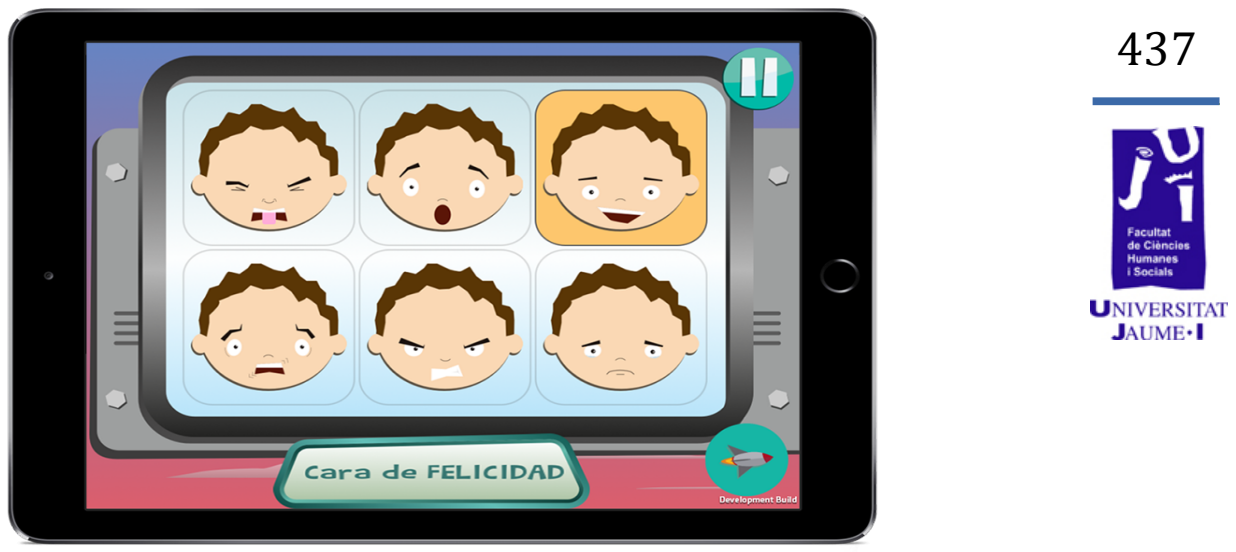

Figura 1. Exemple d'identificar l'emoció de felicitat en el nivell 1.

\section{Nivell 2: Construcció d'expressions facials}

En aquest segon nivell, es requerirà als nens construir diferents expressions facials amb parts de la cara (la boca d'una banda i els ulls i les celles d'una altra), implicats en gestos d'emoció.

De nou, hi ha un total de 12 ítems (dos per a cada expressió facial: feliç, trist, fàstic, por, enuig, sorpresa).

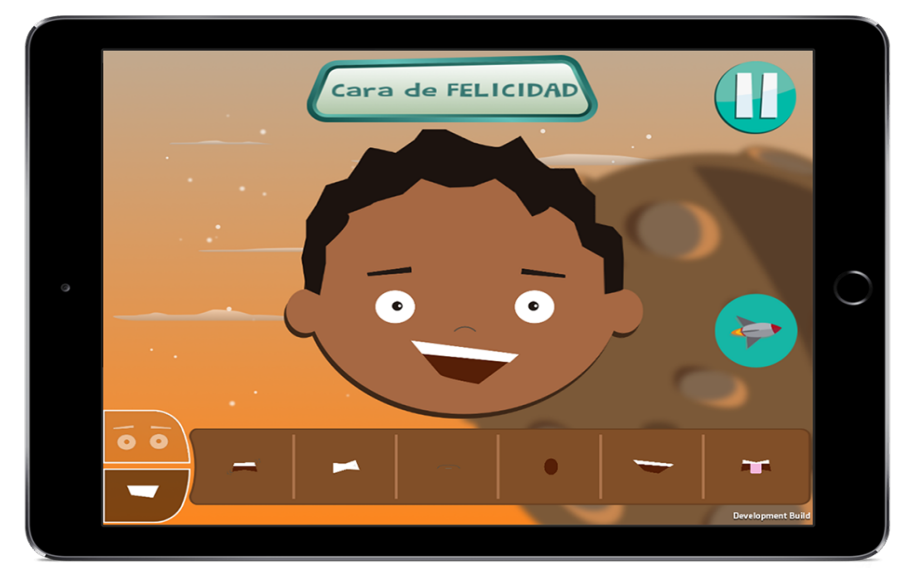

Figura 2. Exemple de construir l'emoció de felicitat en el nivell 2.

\section{Nivell 3: Identificació d'emocions a partir de situacions}

En aquest nivell, després de mostrar les diferents situacions d'una història, els nens hauran d'identificar l'emoció que pensen que el personatge principal sent (entre sis expressions donades). Per aconseguir aquest objectiu, els nens han d'entendre la causa de l'emoció, que consisteix en la comprensió de la situació o context donat.

De nou, hi ha un total de 12 ítems (dos per a cada expressió facial: feliç, trist, fàstic, por, enuig, sorpresa). En la Figura 3, s'explica l'exemple d'una de les històries per avaluar tristesa. 


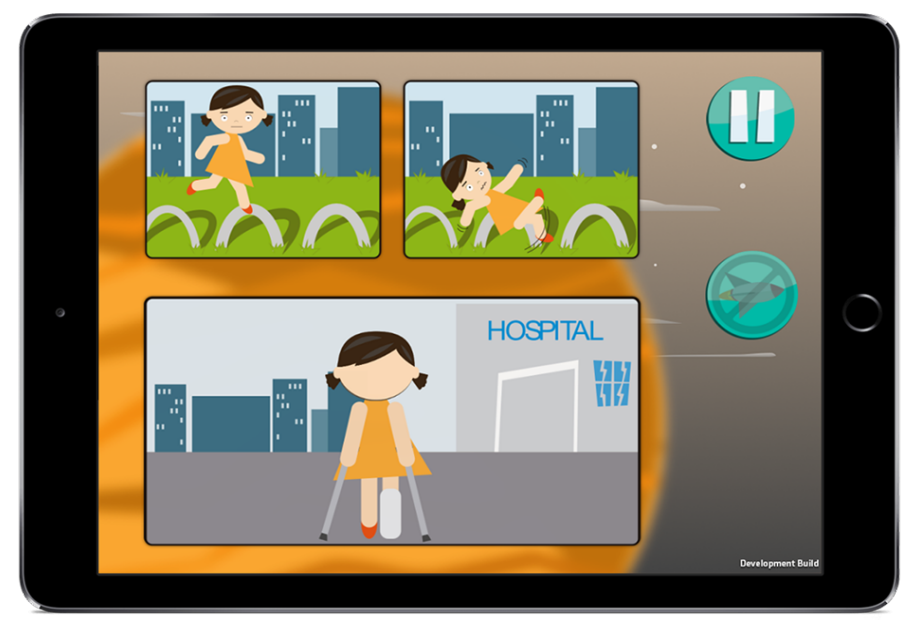

Figura 3. Exemple d'una situació en el nivell 3, on s'ha d'identificar l'emoció de la protagonista després del que li ha ocorregut.

Nivell 4: Reconeixement de les emocions basades en elements cognitius

Aquest nivell avalua les emocions basades en el record (per exemple, quan mirem una foto del passat) o en falses creences en una situació.

De nou, hi ha un total de 12 ítems, on sempre hi ha un canvi en l'experiència emocional del protagonista (abans i després), en relació amb una experiència cognitiva. En la Figura 4 s'adjunta un exemple d'un dels ítems per a avaluar una emoció basada en una falsa creença (és a dir, la nena de la història primer està contenta perquè pensa que en la caixa trobarà galetes).

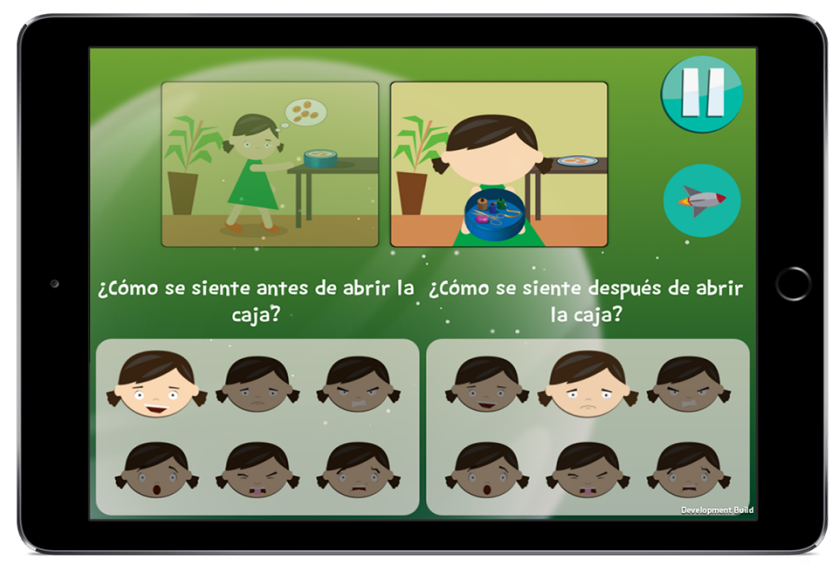

Figura 4. Exemple d'una situació en el nivell 4, on s'ha d'identificar l'emoció basada en elements cognitius. 
Nivell 5: Reconeixement d'emocions ocultes (aparença/realitat emocional)

En aquest nivell, els nens han d'entendre que les persones de vegades amaguen les seues emocions reals i en mostren unes altres, és a dir, pot haver-hi una discrepància entre les emocions que una persona mostra a l'exterior i el que realment sent internament.

$\mathrm{Hi}$ ha un total de 12 ítems, dels quals en el $50 \%$ de les situacions el protagonista amaga una emoció negativa (p. ex. tristor) i en el $50 \%$ n'amaga una de positiva (p. ex. felicitat). A més, en aquest nivell s'afegeix la cara neutra, ja que és essencial per dissimular una emoció.

En la Figura 5 s'adjunta un exemple d'un dels ítems per a avaluar una emoció basada en una falsa creença (és a dir, la nena de la història primer està contenta perquè pensa que en la caixa trobarà galetes).

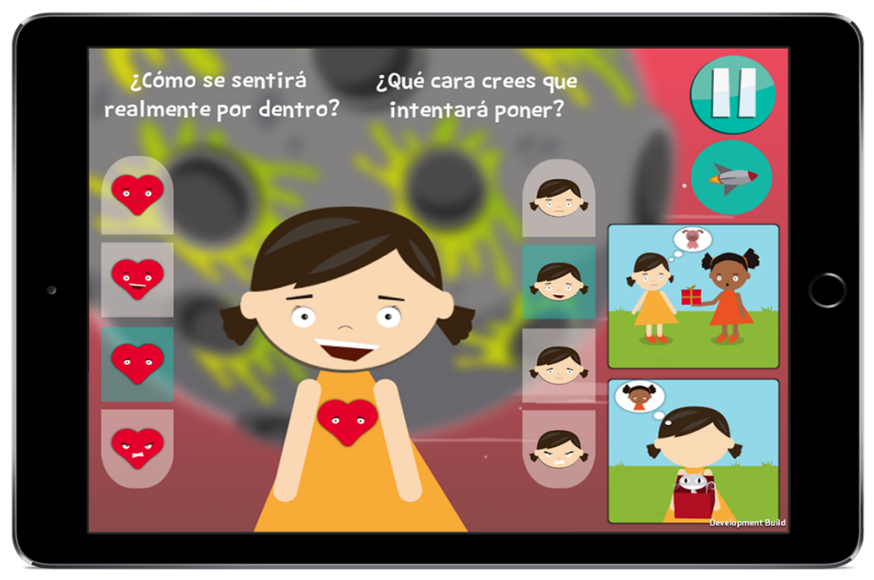

Figura 5. Exemple d'una situació en el nivell 5, on s'ha d'identificar l'emoció interna de la protagonista i l'externa.

\subsection{Procediment}

Per a dur a terme aquesta investigació, en primer lloc es va contactar amb un centre escolar privat de la província de Castelló i s'hi va seleccionar un nen amb DT. En paral-lel, es va contactar amb un centre privat de psicologia per seleccionar un nen amb TEA nivell 1.

Posteriorment, es van sol-licitar tots els permisos necessaris per a dur a terme l'estudi i l'autorització dels pares dels menors. Una vegada es va tenir tot el que era necessari, es va administrar la tasca als nens de manera individual, i es va recollir feedback sobre com els nens executaven cada nivell (dificultats que s'hi 'observaven, no enteniment dels ítems, etc.) per tal de realitzar les millores escaients. 


\section{Resultats}

Resultats relacionats amb el primer objectiu

Després de l'avaluació dels dos nens, es va observar que el nen diagnosticat amb TEA tenia dificultats en 3 dels 5 nivells, mentre que el nen amb DT els va realitzar correctament tots. En concret, el nen amb TEA presenta dificultats en el nivell 2 (quan se seleccionen els ulls i les celles), en el nivell 3 (confonent emocions amb valència negativa: tristesaenuig, tristesa-fàstic) i en el nivell 5 (incapaç d'identificar les emocions internes i externes).

\section{Resultats relacionats amb el segon objectiu}

Després de l'anàlisi de les dades i del feedback, es van realitzar els canvis en l'app següents:

- Respecte el nivell 1, es va modificar la transició d'ítem a ítem (rapidesa de l'aparició de les cares) i es va augmentar la mida de les expressions facials (per permetre que el nen puga seleccionar el que necessite més còmodament).

- En el nivell 2 es van afegir unes petites instruccions visuals, que faciliten al nen la selecció del document o resposta.

- En el nivell 3, es va modificar una de les històries per donar suport visualment millor la comprensió de l'emoció (la d'alegria basada en una invitació a jugar). La resta d'històries resultaven comprensibles.

- En el nivell 4 es va canviar una història i se la va dotar de detalls més deliberats (emoció basada en record trist), ja que es va veure que era confusa i no es comprenia com s'esperava.

- Finalment, en el nivell 5 es van modificar dues de les històries i la distribució de la imatge a la pantalla, de manera que aquesta era més accessible per comprendre-la.

\section{Discussió i conclusions}

Al principi d'aquest estudi, es plantejaven dos objectius principals. El primer era tractar de comparar el funcionament de l'app com a instrument d'avaluació en un nen de 12 anys amb TEA N1 i un altre de la mateixa edat amb DT. D'aquest primer objectiu s'hipotetitzava que s'apreciarien diferències en l'execució de l'app entre els dos casos (DT i TEA N1).

Després de la realització de la investigació, es pot afirmar que s'ha confirmat la hipòtesis plantejada ja que, comparant els dos casos, es veu que el nen amb TEA N1 té una pitjor execució en la major part de nivells en comparació amb el nen control amb DT.

El nen amb TEA N1, com que té 12 anys, els primers nivells -per tant més senzills- els superava sense cap inconvenient. En canvi les 
diferències més notables s'aprecien en els nivells 3 i 5 , ja que aquest nen confon les emocions neutres 0 amb valència negativa, com ara sorpresa 0 fàstic amb l'emoció tristesa.

El segon objectiu plantejat era provar de manera pilot l'eficàcia de l'app EMOCIONATEST per a l'avaluació de la competència emocional en nens i nenes amb TEA entre 3 i 12 anys. En aquest cas, no hi havia cap hipòtesi, ja que l'aplicació es va provar i es va prendre nota de les errades per resoldre-les de cara al futur

Una vegada realitzada la prova pilot d'aquesta aplicació mòbil, es pot afirmar que sí que permet avaluar la competència emocional en els nens d'edat escolar. També permet establir diferències entre nens i nenes amb TEA, tant quantitatives com qualitatives.

Com s'ha comentat abans, mentre s'administrava aquesta ferramenta, es va anar anotant tot el feedback que anava eixint, i s'anaven apreciant distintes millores a realitzar en l'app en fase experimental i que caldria modificar de cara a l'aplicació final per poder millorar-ne el rendiment i les prestacions.

En primer lloc, per la dificultat de la comprensió, es va eliminar un nivell (emocions basades en la comprensió dels desitjos del protagonista), de manera que finalment queda formada per 5 nivells, en lloc de $6 \mathrm{com}$ al principi. Aquest nivell feia massa llarga l'avaluació i requeria massa explicacions verbals. A més, es va considerar que alguns d'aquests aspectes ja s'avaluaven en el nivell següent (actual nivell 4). En segon Iloc, es van modificar alguns aspectes més superficials dels 5 nivells.

Actualment, s'ha contactat amb diferents escoles públiques de la província de Castelló (amb aules de comunicació i llenguatge integrades), en les quals es procedirà a validar la versió definitiva de l'app tant amb població normotípica, com amb TEA, juntament amb altres tests estandarditzats (qüestionaris per a pares i altres mesures de funcionament socioemocional).

En paral·lel, s'han creat dos manuals:

1. Un manual d'avaluació, amb l'objectiu de donar les directrius necessàries per a administrar l'app als futurs professionals que la utilitzen. En aquest manual, apareixeran les instruccions i pautes a seguir i les narracions que donaran suport al desenvolupament visual de l'app, etc.

2. Un manual d'intervenció, amb l'objectiu d'emprar l'app i el seu contingut en l'àmbit didàctic a les aules. En aquest material apareixen directrius d'intervenció per als professionals i es proposa una sèrie d'exercicis a realitzar tant amb l'app, com amb el contingut corresponent ( $p$. ex. imprés $i$ treballat de manera manipulativa).

La creació d'una app per a l'avaluació en la competència emocional de nens i nenes amb TEA suposa una novetat per diversos motius: en primer lloc, perquè no hi ha materials per a avaluar el component 
emocional de manera comprensiva; en segon $1 \mathrm{loc}$, perquè els mètodes existents obliden el component motivador, no solen estar adaptats a les característiques dels nens i nenes amb TEA i són de difícil accés, i en tercer lloc, perquè és una oportunitat per a donar una garantia a professionals d'atenció psicoeducativa sobre un mètode d'intervenció en un àrea tan complexa com és la competència social.

Al contrari que moltes app existents amb finalitats comercials o purament lúdiques, es busca donar una garantia científica al mètode educatiu proposat, ja que comportarà un rigor metodològic tant en el disseny com en la implementació per avalar la millora de la competència emocional.

Els resultats de la validació d'EMOCIONATEST seran beneficiosos tant per a la comunitat científica, com social i tecnològica:

- Científicament, suposarà un avenç important en la recerca de mètodes d'intervenció basats en estudis empírics. Així mateix, permetrà demostrar l'efectivitat de les aplicacions mòbils com a mètode educatiu en el camp psicoeducatiu.

- Tecnològicament, s'obtindrà un producte motivador, atractiu i senzill d'utilitzar per part de les persones implicades en l'educació dels nens i les nenes amb TEA. A més, l'aplicació mòbil es pot traduir a diferents idiomes, tot i que en principi es dissenyarà en castellà $i$ valencià. A més, la ferramenta comptarà amb un suport científic garantit per un equip d'investigació expert en temàtiques de competència socioemocional i trastorns del desenvolupament.

- Pel que fa a l'àmbit econòmic i social, l'aplicació es compartirà $a m b$ els diferents sectors interessats en l'àmbit autonòmic $i$ estatal (centres educatius, serveis psicopedagògics escolars, associacions d'Asperger i TEA, etc.), de manera que serà una ferramenta que també podran utilitzar altres nens i nenes que presenten dificultats en la competència emocional ( $p$. ex. síndrome de Down o TDAH).

\section{Agraïments}

Els autors d'aquest article volen agrair la participació a les persones de San Cristóbal Centres Educatius i del Centre de Psicologia Camins que van participar d'aquest treball, així com l'ajuda finançada atorgada pel projecte Herramienta para la evaluación en la competencia emocional de niños y niñas con Trastorno del Espectro Autista (Código: VAL-2004-04), subvencionat per l'Acción 4.1. del Plan de Promoción de la Investigación 2014 - Convocatoria StartUJI de Valorización de Resultados de Investigación. 
American Psychiatric Association (2013): Diagnostic and Statistical Manual of Mental Disorders (5th ed.), Washington, D.C.

- (2008): Diagnostic and Statistical Manual of Mental Disorders: DSM-IV$T R$. (4th ed.), Washington, DC.

BARON-Cohen, S. i altres (eds.) (2001): "The "Reading the Mind in the Eyes" Test Revised Version: A Study with Normal Adults, and Adults with Asperger Syndrome or High-Functioning Autism", Journal of Child Psychology \& Psychiatry \& Allied Disciplines, 42, p. 241-251.

Deruelle, C. i altres (2004): "Spatial Frequency and Face Processing in Children with Autism and Asperger Syndrome», Journal of Autism and Developmental Disorders, 34 (2), p. 199-210

EICH, E. i J. W. SCHOOLER, (2000): «Cognition/Emotion Interaction», EICH, E., J. F. Kilhstrom, G. H. Bower, J. P. Forgas i P. M. Niedenthal (Eds.), Cognition and Emotion, Oxford University Press, Oxford, p. 3-29.

FRITH, U. (2003): «Autism: Explaining the Enigma» ( $2^{\text {nd }}$ ed.), Blackwell, Oxford.

Giménez-DAsí, M. i L. Quintanilla (2009): "“Competencia” social, "competencia" emocional: una propuesta para intervenir en Educación Infantil», Infancia y Aprendizaje, 32:3, p. 359-373

GómeZ, J. L. C. i V. A. GARCíA, (2012): «Tecnologías de la información y la comunicación: aplicaciones en el ámbito de los trastornos del espectro del autismo", Siglo Cero: Revista Española sobre Discapacidad Intelectual, 43(242), p. 6-25.

Grossman, J. B. i altres (ed.) (2000): «Verbal Bias in Recognition of Facial Emotions in Children with Asperger Syndrome», Journal of Child Psychology and Psychiatry and Allied Disciplines, 41, p. 369-379.

HoBson, R. P. (1986): «The Autistic Child's Appraisal of Expressions of Emotion: A Further Study», Journal of Child Psychology and Psychiatry, 27, p. 671-680.

KLIN, A. (2000): «Attributing Social Meaning to Ambiguous Visual Stimuli in Higher-Functioning Autism and Asperger Syndrome: the Social Attribution Task», J Child Psychol Psychiatry, 41, p. 831-46.

LoVELAND, K. A. i altres (1997): «Emotion Recognition in Autism: Verbal and Non-Verbal Information", Development and Psychopathology, 9, p. 579593.

YIRMiYA, N. i ALtRES (1992): «Empathy and Cognition in High-Functioning Children with Autism», Child Development, 63, p. 150-160. 